\title{
Treatment of a benign, anastomotic refractory rectal stricture with an AXIOS stent
}
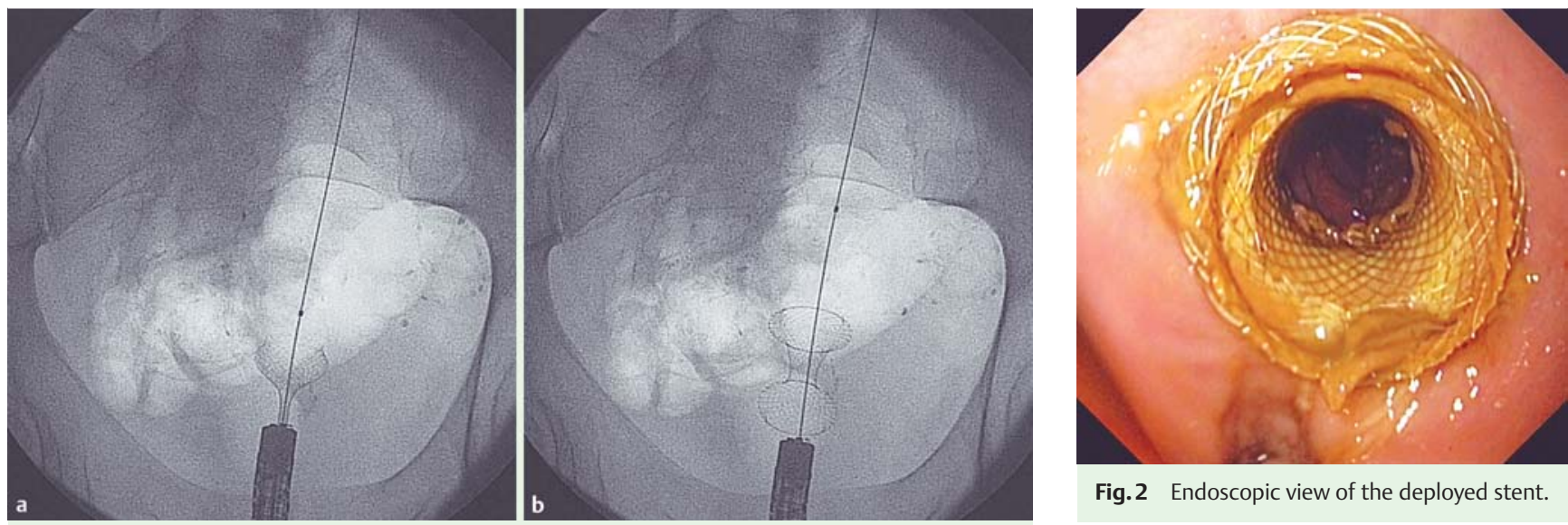

Fig. 2 Endoscopic view of the deployed stent.

Fig. 1 a, b Placement of a fully covered, self-expanding, metal stent under radiologic vision, for treatment of a benign anastomotic rectal stricture.

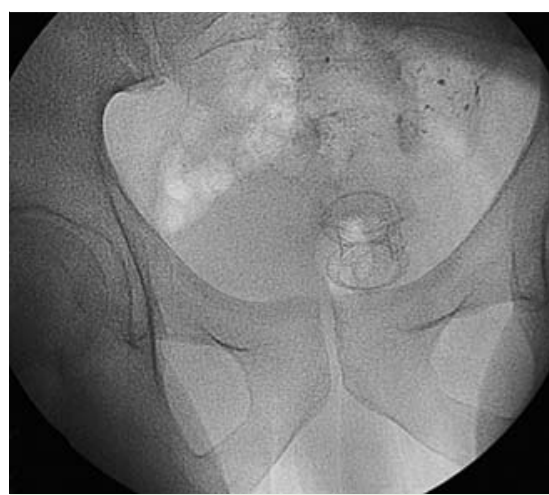

Fig. 3 Radiologic view of the fully expanded stent inside of the stenosis.

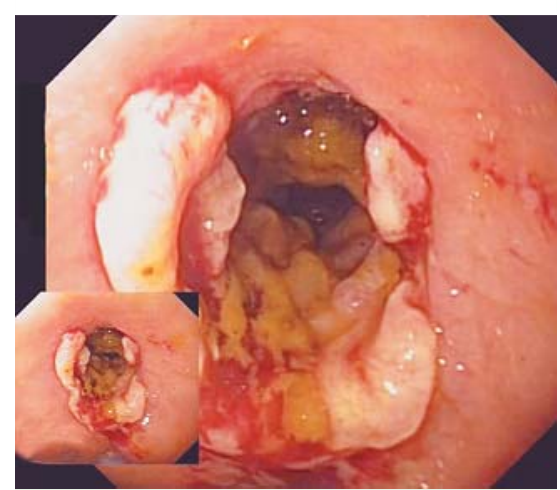

Fig. 4 Endoscopic view of the stenosis immediately after withdrawal of the stent.

performed using a through-the-scope, over-the-wire balloon under fluoroscopic guidance. Despite this aggressive protocol, the stenosis remained tight, with a diameter of $<10 \mathrm{~mm}$. Therefore, placement of a novel, fully covered, self-expanding metal stent (SEMS) was proposed (AXIOS AXS15-10; Xlumena Inc., Mountain View, California, USA) ( $\bullet$ Video 1$)$. The stent was placed under endoscopic and radiologic guidance ( $\bullet$ Fig. 1, $\odot$ Fig. 2 ).

The prosthesis was well tolerated without complications or the need for analgesia (৫ Fig. 3), and was removed 40 days later $(\bullet$ Fig. 4, $\odot$ Video 1 ). The patient remained asymptomatic and with adequate intestinal transit after 2 months' follow-up. SEMS are not widely used for benign colon disease [1]. Risks associated with the use of SEMS include perforation, chronic

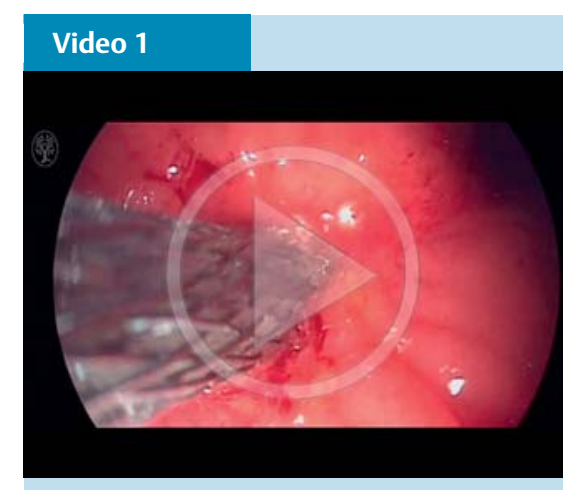

Placement and removal of a fully covered, selfexpanding, metal stent for the treatment of postsurgical rectal stricture.

abdominal pain, migration or late prosthesis obstruction. Biodegradable stents are an alternative and their placement is an effective treatment in anastomotic strictures of the colon, as they are more flexible than metal or plastic stents and do not require removal because they disintegrate after 11 - 12 weeks [2]. However, these stents are wider, longer, and thus poorly tolerated, especially in locations close to the anus.

The patient presented in this report had a complex, severe, and refractory anastomotic stenosis, located very close to the anus, and therefore was not a candidate for treatment with currently available prostheses. The AXIOS echo-endoscopic stent, which was designed for treatment of pancreatic pseudocysts, is a completely covered SEMS with proximal and distal 
flanges and a smaller central section, which measures 1.0 or $1.5 \mathrm{~cm}$ in diameter. This stent is shorter than other stents and, as demonstrated in the current case, may also be used to treat benign, complex, anastomotic rectal strictures.

Endoscopy_UCTN_Code_TTT_1AQ_2AF

Competing interests: None

Felipe Martínez Alcalá ', Felipe R. Martínez-Alcalá García ${ }^{1}$, Andres SánchezYague $^{2}$, Alvaro Martínez-Alcalá García', Jose Antonio Ciria Avila' ${ }^{1}$, Jose Manuel Perez Pozo ${ }^{1}$

${ }^{1}$ CIDMA (Centro de Innovaciones Digestivas Martínez Alcalá), Sevilla, Spain

${ }^{2}$ Hospital de Costa del Sol, Marbella, Málaga, Spain

\section{References}

1 van Hooft JE, van Halsema EE, Vanbiervliet G et al. Self-expandable metal stents for obstructing colonic and extracolonic cancer: European Society of Gastrointestinal Endoscopy (ESGE) clinical guideline. Endoscopy 2014; 46: 990-1002

2 Rejchrt S, Kopacova M, Brozik J et al. Biodegradable stents for the treatment of benign stenoses of the small and large intestines. Endoscopy 2011; 43: $911-917$

\section{Bibliography}

Dol http://dx.doi.org/ 10.1055/s-0034-1392676 Endoscopy 2015; 47: E413-E414

(c) Georg Thieme Verlag KG Stuttgart · New York ISSN 0013-726X

\section{Corresponding author}

Alvaro Martínez-Alcalá García, MD

Calle San Vicente 36

Cp: 41002 Sevilla

Spain

Fax: +34-66-2372216

alvaromalcala@gmail.com 